\title{
Static Mechanical Properties and Modal Analysis of a Kind of Lift-Drag Combined-Type Vertical Axis Wind Turbine
}

\author{
Fang Feng $\mathbb{D},{ }^{1,2}$ Chunming $Q u^{3}$ Shouyang Zhao, ${ }^{3}$ Yuedi Bai, ${ }^{3}$ \\ Wenfeng Guo, ${ }^{3}$ and Yan $L i \mathbb{D}^{2,3}$ \\ ${ }^{1}$ College of Science, Northeast Agricultural University, Harbin, China \\ ${ }^{2}$ Heilongjiang Provincial Key Laboratory of Technology and Equipment for Utilization of Agricultural Renewable Resources in Cold \\ Region, Harbin 150030, China \\ ${ }^{3}$ College of Engineering, Northeast Agricultural University, Harbin, China
}

Correspondence should be addressed to Fang Feng; fengfang@neau.edu.cn and Yan Li; liyanneau@163.com

Received 27 October 2017; Revised 5 July 2018; Accepted 30 July 2018; Published 7 August 2018

Academic Editor: Tareq S. Z. Salameh

Copyright (C) 2018 Fang Feng et al. This is an open access article distributed under the Creative Commons Attribution License, which permits unrestricted use, distribution, and reproduction in any medium, provided the original work is properly cited.

\begin{abstract}
In order to explore a set of methods to analyze the structure of Lift-Drag Combined-Type Vertical Axis Wind Turbine (LD-VAWT), a small LD-VAWT was designed according to the corresponding Standards and General Design Requirements for small vertical axis wind turbines. The finite element method was used to calculate and analyze the static mechanical properties and modalities of main parts of a kind of small-scale LD-VAWT. The contours of corresponding stress and displacement were obtained, and first six-order mode vibration profiles of main parts were also obtained. The results show that the main structure parts of LD-VAWT meet the design requirements in the working condition of the rated speed. Furthermore, the resonances of all main parts did not occur during operation in the simulations. The prototype LD-VAWT was made based on the analysis and simulation results in this study and operated steadily. The methods used in this study can be used as a reference for the static mechanical properties and modal analysis of vertical axis wind turbine.
\end{abstract}

\section{Introduction}

The vertical axis wind turbine (VAWT) has a simple structure and does not need special device to catch the wind. In addition, it is environmentally friendly; therefore, it has a rapid development in recent years. Among them, the Straight-Bladed Vertical Axis Wind Turbine (SB-VAWT) has been studied more deeply due to better power characteristics and higher transfer efficiency of wind energy. However, the starting characteristic is not well, which is one of the important factors restricting the development of SB-VAWT [1]. Therefore, improving the starting characteristics of SBVAWT has become the research focus for many scholars [2]. Tang Jing et al. [3] have installed wind hood at the top and bottom of the SB-VAWT to increase the flow speed which can improve the start-up performance of wind turbine; $\mathrm{Wu}$ Zhicheng et al. [4] have changed symmetric wind rotor into eccentric wind rotor in order to improve the starting torque of the wind turbine. The theoretical calculations and model tests for the aerodynamic characteristics are numerous; however, the analysis of static and dynamic mechanical properties of wind turbine structure for designing prototype is little. M. SaqibHameed et al. [5] have shown that larger centrifugal load mainly causes bending deformation of blade and used finite element method to compare the mechanical properties of blades made in aluminum and glass fibre reinforced plastic (FRP). The results show that FRP is more suitable to blade material; Lin Wang [6] has used the finite element analysis and genetic algorithm to optimize the structure and weight of blade in the requirement of strength; Zhang Tingting et al. [7] have analyzed the dynamics of the main axis of Darrieus wind turbine, calculated the range of wind speed which can avoid resonance, and obtained the optimal thickness of tube wall of main axis; Wang Jianyu [8] has analyzed the influence of blade shedding vortex on the dynamics of tower and main axis. The research shows that shedding vortex can induce 
TABLE 1: Basic structural parameters of LD-VAWT.

\begin{tabular}{lcc}
\hline Name & Symbol & Value \\
\hline Rated power $[\mathrm{kW}]$ & $P$ & 3 \\
Rated wind speed $[\mathrm{m} / \mathrm{s}]$ & $V$ & 10 \\
Wind rotor diameter $[\mathrm{mm}]$ & $d$ & 4000 \\
Wind rotor height $[\mathrm{mm}]$ & $H$ & 5200 \\
Number of main blades & $N$ & 3 \\
Chord length of main blade $[\mathrm{mm}]$ & $\mathrm{c}$ & 400 \\
Airfoil of main blade & - & NACA0018 \\
Attack angle of main blade $\left[{ }^{\circ}\right]$ & $\beta$ & 0 \\
Drag rotor diameter $[\mathrm{mm}]$ & $d$ & 700 \\
Drag rotor height $[\mathrm{mm}]$ & $h$ & 2600 \\
Mounting position of drag rotor $[\mathrm{mm}]$ & $\mathrm{S}$ & 250 \\
\hline
\end{tabular}

resonance; Nidal $\mathrm{H}$. Abu-Hamdeh [9] used ANSYS to model the majority of the structural components of a collapsible vertical axis wind turbine, and data from the mathematical models were used to verify the structure of the turbine and shafts were within acceptable stress and strain limits, the result of the experiments verified the mathematical simulation analysis; Yu Tang [10] used ANSYS Workbench static and modal analysis module to make load analysis of wind turbine internal maintenance lifting platform and obtained the maximum stress of platform bridge structure and place and form of deformation; E. Verkinderen [11] analyzed the coupled structure through a multidegree of freedom system, as well as numerically through the finite element (FE) method of H-Darrieus vertical axis wind turbines; Zheng Li [12] presented a method to simulate wind turbine gearbox system with the multibody drivetrain dynamic analysis software, and the modal analysis of wind turbine gearbox can be carried out on the basis of the multibody dynamic theory. The above researches are only focused on the analysis of common vertical axis wind turbine. However the analysis on the structure of LD-VAWT is little and it does not build a perfect set of designing plan and methods yet. Therefore, this paper will search on the static and dynamic mechanical properties of structure based on a small-scale lift-type vertical axis wind turbine [13-21] and propose a set of suitable research plans and methods as references to other kinds of LD-VAWTs and vertical axis wind turbines.

\section{Design of Wind Turbine}

2.1. Wind Turbine Model. The model of LD-VAWT designed is shown in Figure 1, and the basic structural parameters are shown in Table 1.

2.2. Structure Design of Wind Turbine. (1) Wind Rotor: The wind rotor of LD-VAWT is an important part, which can convert wind energy into mechanical energy. It is composed of main blade, drag rotor, beam, main axis, and so on. The main blade is made of FRP which has characteristics of being light, having high strength, having corrosion resistance, and being manufactured easily. The main blade is hollow and

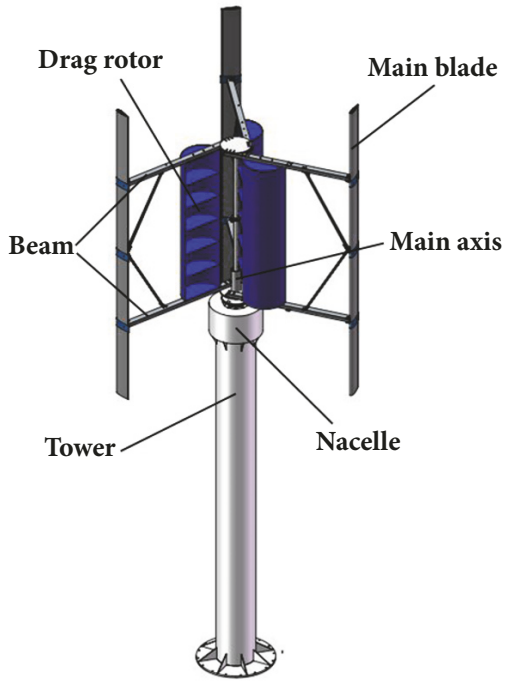

Figure 1: Model of LD-VAWT.

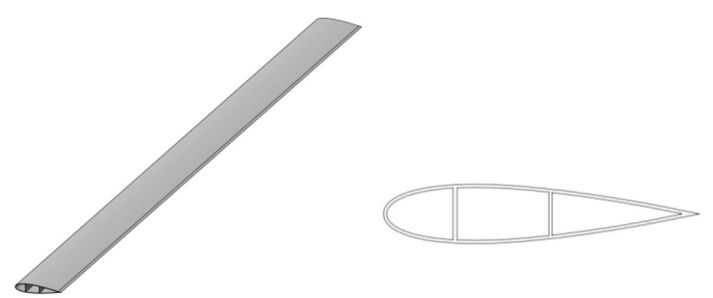

FIgURE 2: The structure of main blade.

stiffened by two ribs, which can reduce the weight of blade. The main blade is shown in Figure 2.

The shape of drag rotor is a semicylindrical surface with thin wall thickness. In order to reduce the weight in the premise of strength requirement, the aluminum alloy material is selected. The thickness of aluminum plate is $3 \mathrm{~mm}$. The structure of drag rotor is shown in Figure 3.

In Figure 1 the beams support the main blades and transmit the torque generated by blade to the main axis. In 


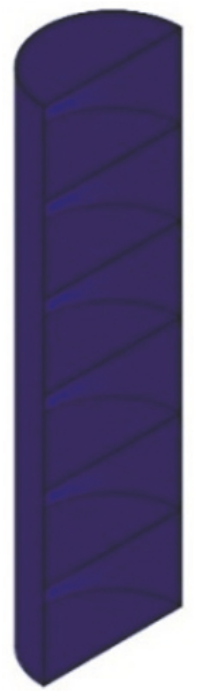

FIgURE 3: The structure of drag rotor.

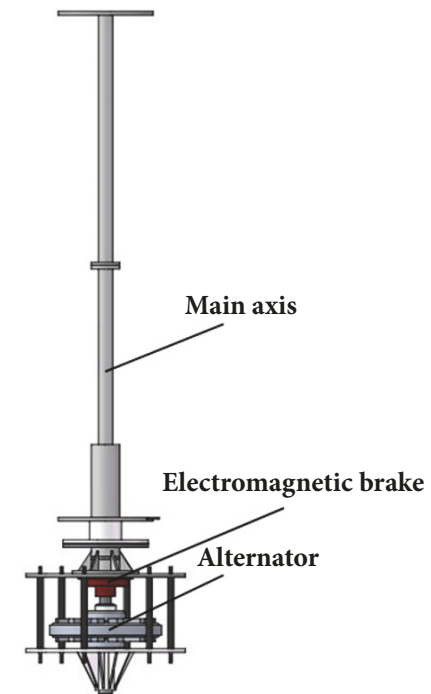

FIGURE 4: The structure of nacelle.

order to enhance bending strength, the square steel is selected as structure of beam. The material of square steel is Q235. The size of cross section is $60 \times 60 \mathrm{~mm}$ and thickness of wall is $3 \mathrm{~mm}$.

(2) Nacelle: The nacelle consists of alternator, electromagnetic brake, main axis, and support bars as shown in Figure 4. The alternator is disc-type permanent magnet synchronous generator. The dynamic friction torque of brake is $400 \mathrm{~N} \cdot \mathrm{m}$.

The main axis in the nacelle is an important part in designing process. The diameter of axis is designed based on the analog method and empirical method. The minimum diameter of main axis is $40 \mathrm{~mm}$ and a pair of angular contact ball bearings with model number 7214 is used.

(3) Tower: The role of the tower is to support and fix the wind rotor and nacelle. The material of tower is Q235,
TABLE 2: The parameters of tower.

\begin{tabular}{lc}
\hline Name & Value \\
\hline Height $[\mathrm{m}]$ & 6 \\
Outside diameter $[\mathrm{mm}]$ & 630 \\
Inside diameter $[\mathrm{mm}]$ & 616 \\
Wall thickness $[\mathrm{mm}]$ & 8 \\
\hline
\end{tabular}

TABLE 3: Material properties of main blade.

\begin{tabular}{lc}
\hline Name & Value \\
\hline Density $\left[\mathrm{kg} / \mathrm{m}^{3}\right]$ & $2 \times 10^{3}$ \\
Elastic Modulus [MPa] & $7.2 \times 10^{4}$ \\
Yield limit [MPa] & 450 \\
Poisson ratio & 0.22 \\
Allowable stress [MPa] & 320 \\
\hline
\end{tabular}

the structure is shown in Figure 1, and the configuration parameters are shown in Table 2.

\section{Static Mechanical Property Analysis Structure}

3.1. Main Blade. The loads of main blade during operation mainly include self-gravity $G_{\mathrm{L}}$, centrifugal force load $F_{\mathrm{rL}}$ caused by the rotation, and aerodynamic load $F_{\mathrm{pL}}$ from wind. According to theoretical calculation, the self-gravity $G_{\mathrm{L}}$ is 312 $\mathrm{N}$, the centrifugal force $F_{\mathrm{rL}}$ is $6843 \mathrm{~N}$, and the wind load $F_{\mathrm{pL}}$ is $95.6 \mathrm{~N}$.

The static mechanical property of main blade is analyzed by finite element method (FEM). The tetrahedral element is selected as mesh type of main blade and the element type is Solid186. Finally, the finite element model of blade has 616368 elements and 212397 nodes. The material of main blade is FRP and the material properties are shown in Table 3.

In order to simulate the connected relation between main blade and beam, a fixed constraint is added at the connection point. Then the wind load is applied on the windward surface of main blade by pressure, the main blade weight is calculated by mass, and gravity acceleration and the centrifugal force are calculated by the rotational inertia load. The loads above are applied on the model of main blade. Finally, the contours of stress and displacement under the rated operation conditions can be obtained as shown in Figures 5 and 6 .

From Figure 5, the maximum stress of blade is $45.4 \mathrm{MPa}$ which appears at the connection between main blade and beam. The limited stress of FRP is $320 \mathrm{MPa}$ and the safety factor is 1.5 in this design. Then the ultimate allowable tensile stress of FRP is $213 \mathrm{MPa}$. According to simulation results, the structural strength of main blade meets design requirements [22]. From Figure 6, the maximum node displacement of main blade appears at the tip of the blade and the value is $15.1 \mathrm{~mm}$, which is larger than the deformation of middle part. It shows that the deformation has less influence on the dynamic characteristics of the wind turbine, which means the structure meets the design requirements $[23,24]$. 


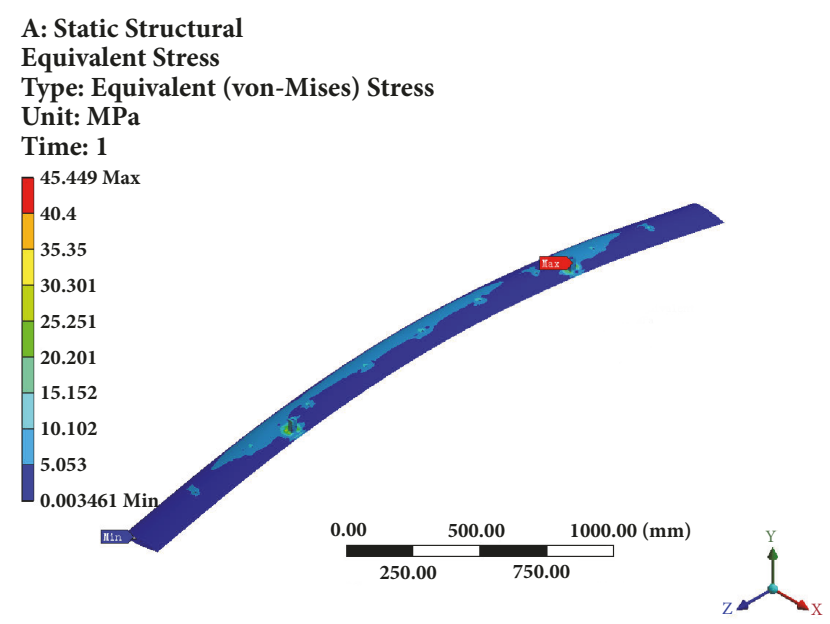

FIGURE 5: Equivalent stress contour of main blade.

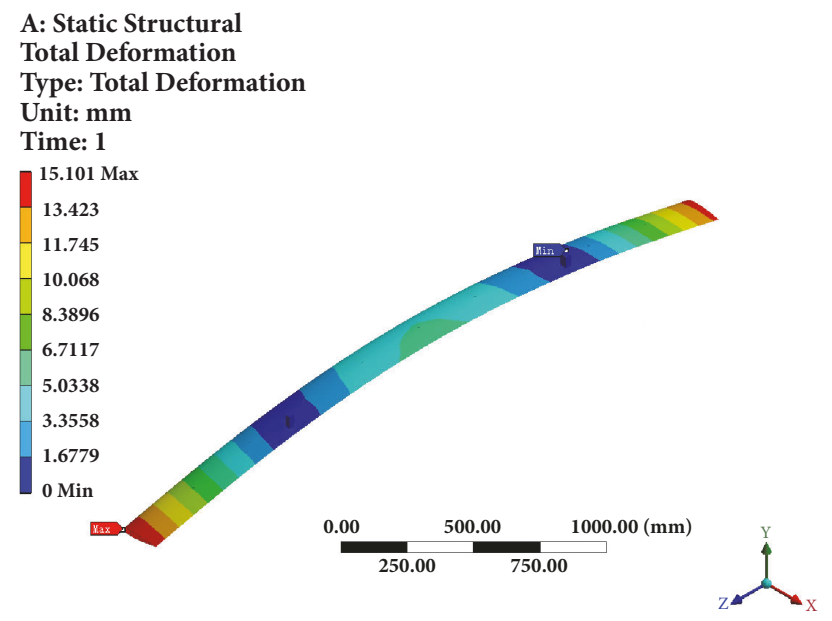

FIGURE 6: Displacement variation contour of main blade.

3.2. Drag Rotor. The calculating method of mechanical property of drag rotor is the same as main blade. The self-gravity $G_{\mathrm{D}}$ is $210 \mathrm{~N}$, the centrifugal force $F_{\mathrm{rD}}$ is $1381.75 \mathrm{~N}$, and the wind load $F_{\mathrm{pD}}$ is $56.77 \mathrm{~N}$.

The solid 185 element is used to mesh and the number of elements and nodes are 457865 and 6956782, respectively. The material of drag rotor is aluminum alloy and the material properties are shown in Table 4.

In the analysis process, the nodes on the upside surface and downside surface of drag rotor are restrained. After calculation, the contours of stress and displacement under the rated condition are obtained as shown in Figures 7 and 8 , respectively.

From Figure 7, the maximum stress of drag rotor is 161.4 MPa which is lower than the limit stress of aluminum alloy. Figure 8 shows that the drag rotor has a little displacement, which satisfies the design requirements.

3.3. Beam. The maximum load of beam happens at the rated speed $100 \mathrm{r} / \mathrm{min}$ of wind rotor. Therefore, analyses of the stress and deformation of beam are processed under the rated speed

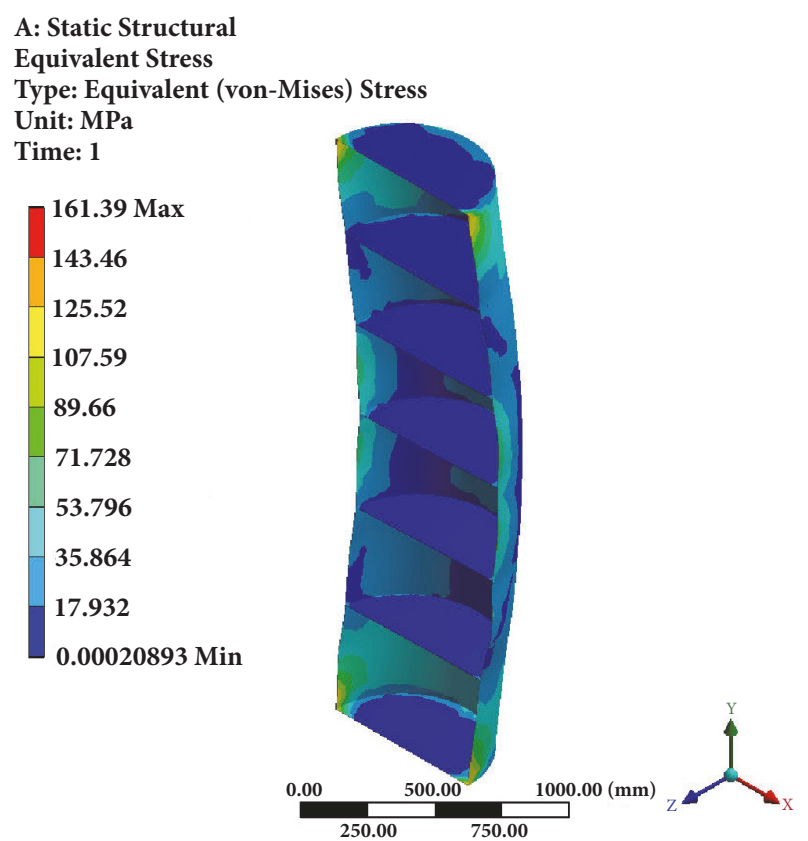

FIGURE 7: Equivalent stress contour of drag rotor.

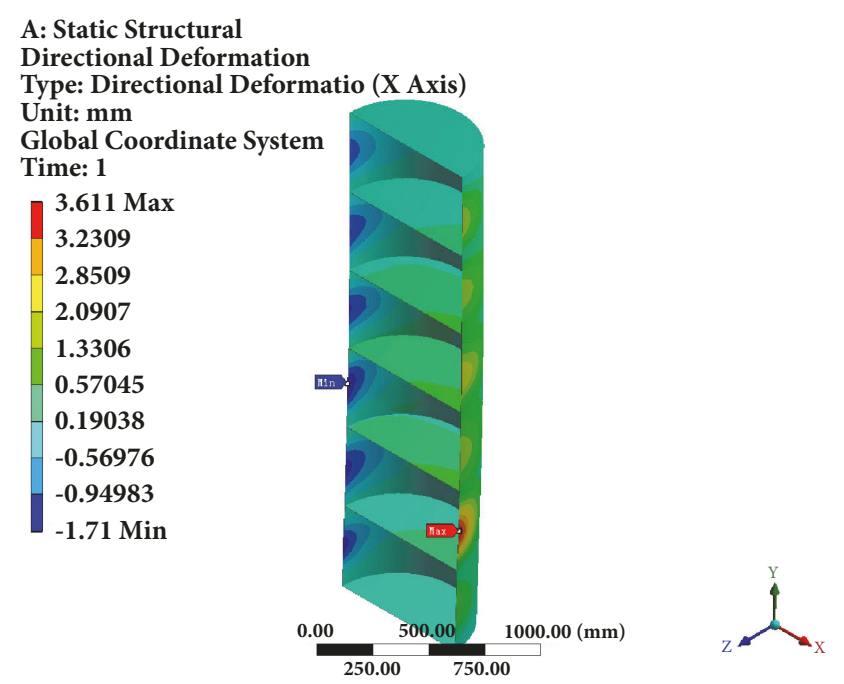

FIGURE 8: Displacement variation contour of drag rotor.

TABLE 4: Material properties of drag rotor.

\begin{tabular}{lc}
\hline Name & Value \\
\hline Density $\left[\mathrm{kg} / \mathrm{m}^{3}\right]$ & $2.7 \times 10^{3}$ \\
Elastic Modulus [MPa] & $6.9 \times 10^{4}$ \\
Yield limit [MPa] & 276 \\
Poisson ratio & 0.33 \\
Tensile strength $[\mathrm{MPa}]$ & 350 \\
\hline
\end{tabular}

condition. Force and torque can be calculated as shown in Table 5. The material of beam is Q235-A (16Mn) and the properties are shown in Table 6. 
TABLE 5: Load distribution of beam.

\begin{tabular}{lc}
\hline Name & Value \\
\hline Self-gravity [N] & 115 \\
Gravity of main blade [N] & 156 \\
Gravity of drag rotor [N] & 105 \\
Torque of main blade $[\mathrm{N} \cdot \mathrm{m}]$ & 119.2 \\
Torque of drag rotor [N·m] & 645 \\
Self-centrifugal force [N] & 120.4 \\
Centrifugal force of main blade [N] & 3421.4 \\
Centrifugal force of drag rotor $[\mathrm{N}]$ & 808.5 \\
\hline
\end{tabular}

TABLE 6: Material properties of beam.

\begin{tabular}{lc}
\hline Name & Value \\
\hline Density $\left[\mathrm{kg} / \mathrm{m}^{3}\right]$ & $7.86 \times 10^{3}$ \\
Elastic Modulus [GPa] & 211 \\
Yield limit [MPa] & 196 \\
Poisson ratio & 0.3 \\
Tensile strength [MPa] & 235 \\
\hline
\end{tabular}

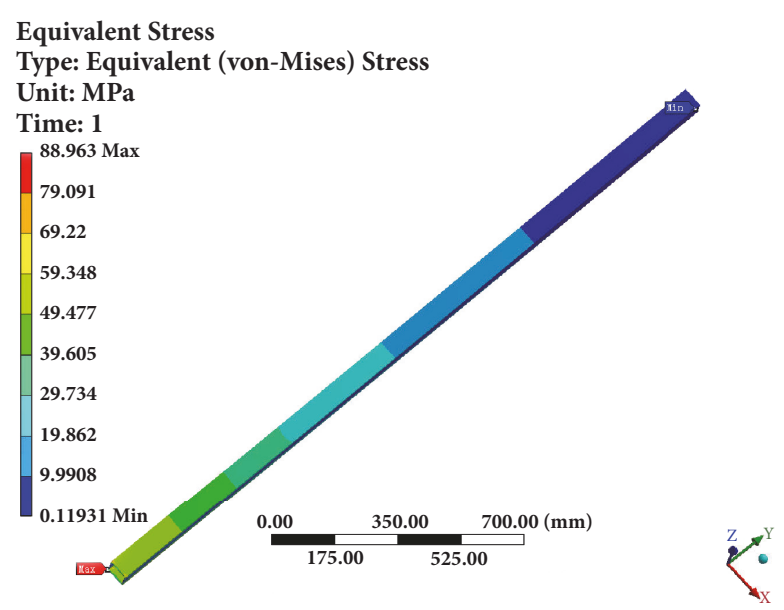

FIGURE 9: Equivalent stress contour of beam.

The Degrees of Freedom (DOF) are constrained on the displacements of $\mathrm{X}, \mathrm{Y}$, and $\mathrm{Z}$ directions at the end of connection position of beam and main axis. Then the gravity load, centrifugal load, and torque load are applied on the model, respectively. The contours of stress and displacement of beam under the rated condition are obtained by calculation as shown in Figures 9 and 10, respectively.

From Figure 9, the maximum stress is $89 \mathrm{MPa}$, which appears at the end of connection position between beam and main axis. Therefore the junction should be strengthened. From Figure 10, the maximum displacement happens at the tip of beam where the lift and drag force is fixed and the maximum deformation is $2.4 \mathrm{~mm}$. The strength of beam needs to meet the checking formula (1)

$$
\delta_{\max }<\frac{[\delta]}{S}
$$

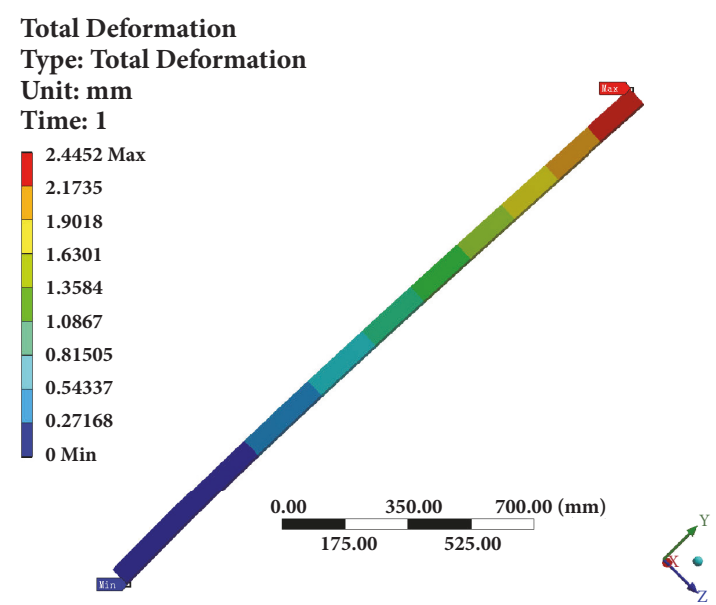

FIGURE 10: Displacement variation contour of beam.

TABLE 7: Received force of main axis.

\begin{tabular}{lc}
\hline Name & Value \\
\hline Gravity of main axis [N] & 630 \\
Gravity of wind rotor [N] & 3250 \\
Torque of wind rotor [N.m] & 1045 \\
Centrifugal force of wind rotor [N] & 0 \\
\hline
\end{tabular}

TABLE 8: Material parameters of main axis.

\begin{tabular}{lc}
\hline Name & Value \\
\hline Density $\left[\mathrm{kg} / \mathrm{m}^{3}\right]$ & $7.86 \times 10^{3}$ \\
Elastic Modulus [MPa] & $2 \times 10^{5}$ \\
Yield limit [MPa] & 400 \\
Poisson ratio & 0.3 \\
Tensile strength $[\mathrm{MPa}]$ & 980 \\
\hline
\end{tabular}

where $\delta_{\max }$ is the maximum stress, $[\delta]$ is yield limit stress of material, in this paper $[\delta]$ is $235 \mathrm{MPa}$, and $[S]$ is safety factor, which is selected as 1.5 .

From the calculation, $\delta_{\max }$ is lower than allowable stress.

The stiffness checking formula is shown as follows:

$$
\frac{\omega_{\max }}{l}<\frac{\left[\omega_{\max } / l\right]}{S}
$$

where $\omega_{\max }$ is the maximum displacement of beam, $2.4 \mathrm{~mm}$, $l$ is the length of beam, $2 \mathrm{~m}$, and $\left[\omega_{\max } / l\right]$ is the allowable deflection of simply supported beam, $1 / 500$.

After calculating, $\omega_{\max } / l=1.2 \times 10^{-3} \mathrm{~m}<\left[\omega_{\max } / l\right] / S=$ $2.6 \times 10^{-3} \mathrm{~m}$, the stiffness of beam under the rated speed meets the design requirements.

3.4. Main Axis. The main axis is mainly subjected to gravity load, centrifugal load, and aerodynamic load. The values of loads are shown in Table 7.

In the static mechanical analysis of main axis, tetrahedral element is used to mesh grids. The numbers of elements and nodes are 87536 and 159853, respectively. The material of main axis is $40 \mathrm{Cr}$, and the properties are shown in Table 8. 


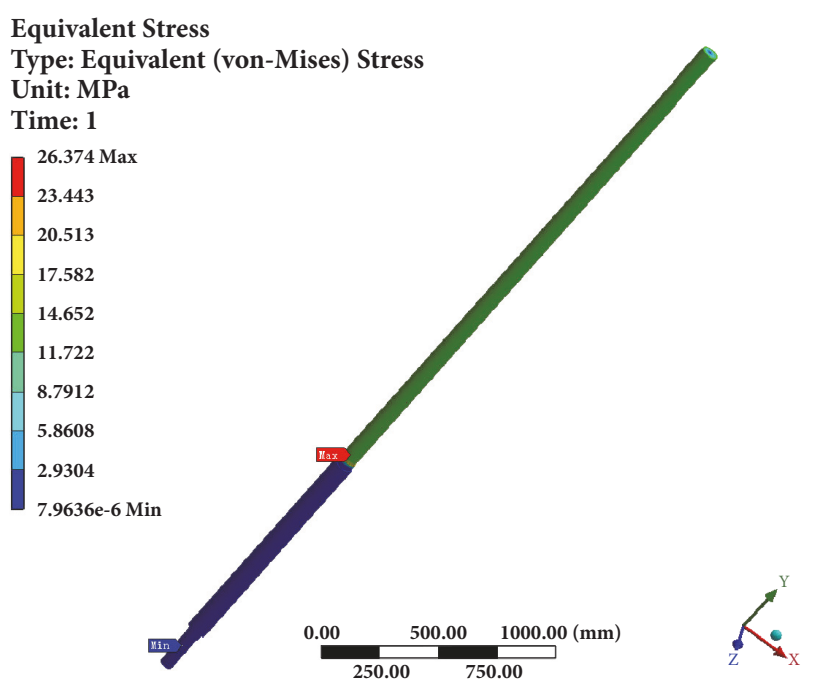

FIGURE 11: Equivalent stress contour of main axis.

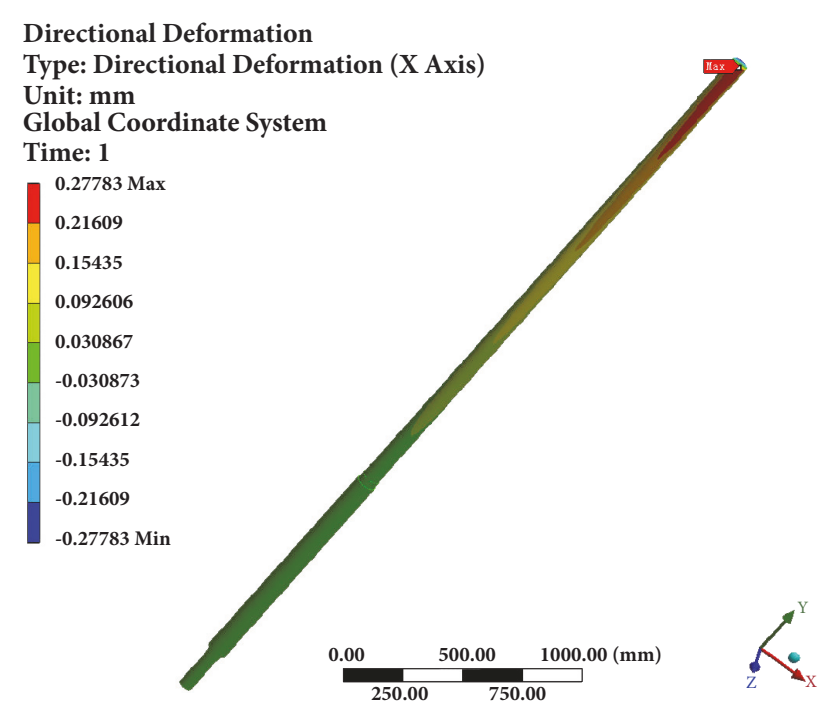

FIGURE 12: Displacement variation contour of axis.

According to the assembly relation, the end of main axis connected with generator is constrained. The self-gravity load of main axis is applied with gravity acceleration, the gravity of wind rotor is applied at mounting position of flange, and the torque of wind rotor is also applied at mounting position of flange. The simulation results are shown in Figures 11 and 12,respectively.

From Figure 11, the maximum stress of main axis is 26.3 MPa which is at the connection position between beam and main axis. From Figure 12, the maximum displacement is at the top of main axis which is $0.27 \mathrm{~mm}$.

According to formula (1), maximum stress of main axis $\delta_{\max }$ is $26.3 \mathrm{MPa}$, limit stress $[\delta]$ is $980 \mathrm{MPa}$, and safety factor $S$ is 3 . The maximum stress $\delta_{\max }$ is lower than allowable stress.
TABLE 9: Load distribution of tower.

\begin{tabular}{lc}
\hline Name & Value \\
\hline Horizontal thrust [N] & 1132.4 \\
Gravity of wind rotor and cabin [N] & 8330 \\
Self-gravity of tower [N] & 8291 \\
Torque of cabin $[\mathrm{N} \cdot \mathrm{m}]$ & 286.5 \\
Wind pressure $[\mathrm{N} / \mathrm{m}]$ & 27.1 \\
\hline
\end{tabular}

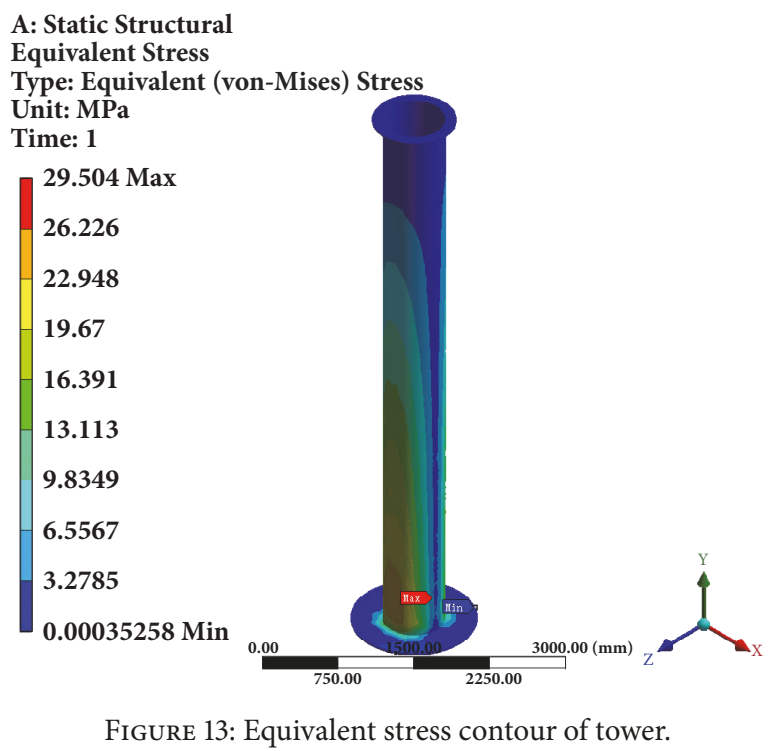

Similarly the stiffness of main axis needs to meet the stiffness checking formula as follows:

$$
y_{\max } \leq 0.0005 l
$$

where $y_{\max }$ is the maximum deformation of main axis and $l$ is the length of main axis, $3400 \mathrm{~mm}$.

The calculation result shows that the maximum deformation of main axis is $0.27 \mathrm{~mm}$.

3.5. Tower. The tower is mainly subjected to horizontal thrust of the wind rotor, the gravity of wind rotor and nacelle, selfgravity, the torque of wind rotor, and the wind pressure acting on the tower. The values of loads distributing on the tower are shown in Table 9.

The material of tower is Q235 and the solid 185 is selected as element type. The numbers of elements and nodes are 15696 and 30864, respectively.

The bottom of tower is constrained. The above loads are applied on the model of tower and the contours of stress and deformation of tower are shown in Figures 13 and 14, respectively.

From Figure 13, the maximum stress of tower is $29.5 \mathrm{MPa}$ which appears at the bottom of tower. From Figure 14, the maximum deformation of tower is $5.3 \mathrm{~mm}$. According to the engineering experience of tower designing [25], the maximum deformation of tower should be less than $0.5 \sim$ $0.8 \%$ of its height for tower. The limit stress of Q235 is 


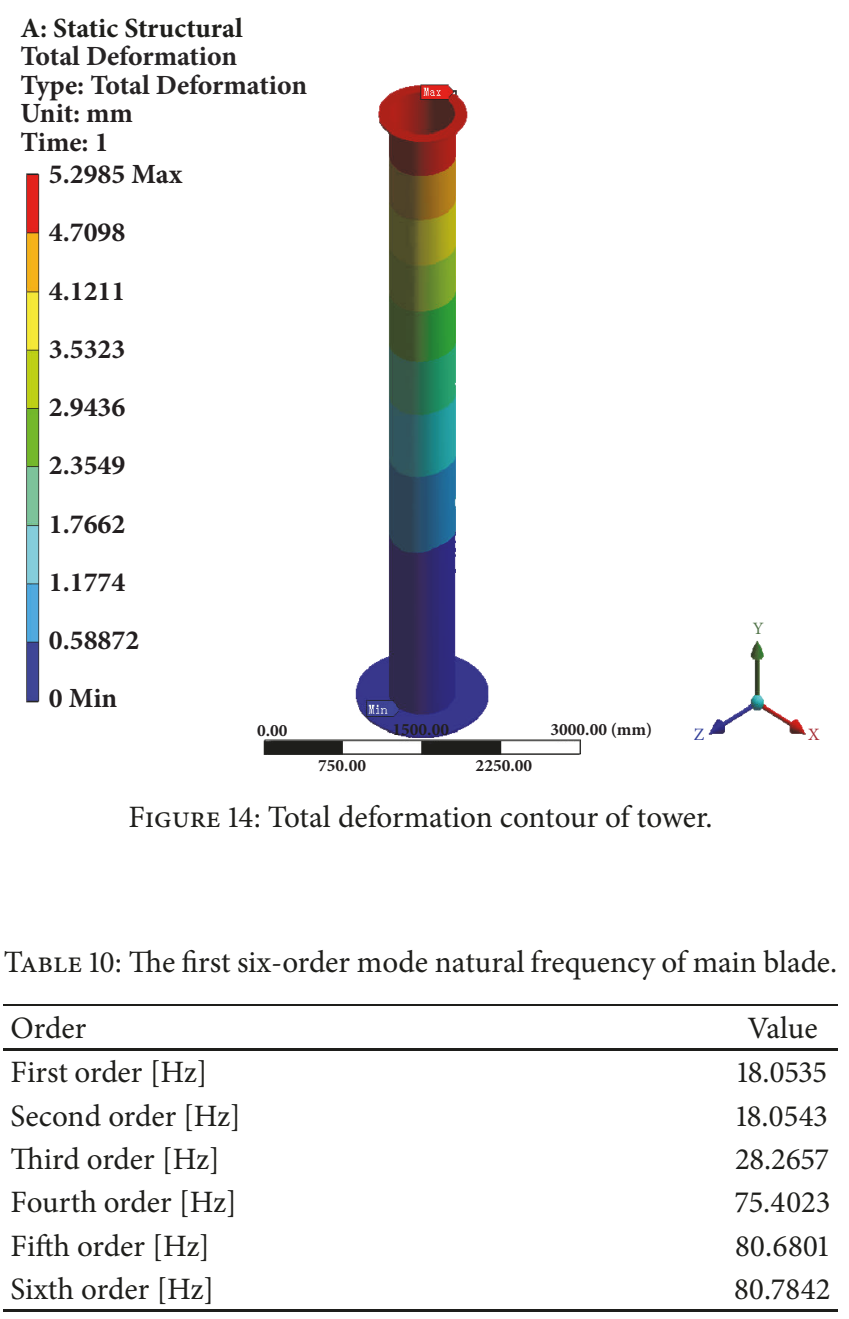

156.7 MPa which is higher than the maximum stress $29.5 \mathrm{MPa}$ in Figure 14.

\section{Modal Analysis}

When the wind turbine works in natural environment, the load is complex and changeable. The power of air, inertia force, and elasticity force applied on the blades of wind turbine can make blade and tower deform and oscillate. If the frequency of exciting force approaches the natural frequency of the structure, the resonance may lead to damage of wind turbine. In order to avoid resonance, the natural frequency of wind turbine should be different from the one of wild exciting force. Therefore, the modal analysis should be carried out during the structural design of wind turbine.

4.1. Main Blade. The model of main blade used in the modal analysis is the same as statistic analysis. The low-order mode of main blade has a great influence on stability and fatigue of blade, and the first six-order modes and the natural frequencies are calculated which are shown in Table 10. The vibration modes are shown in Figure 15.
TABLE 11: The first six-order mode natural frequency of drag rotor.

\begin{tabular}{lc}
\hline Order & Value \\
\hline First order $[\mathrm{Hz}]$ & 50.2653 \\
Second order $[\mathrm{Hz}]$ & 50.3117 \\
Third order $[\mathrm{Hz}]$ & 50.3735 \\
Fourth order $[\mathrm{Hz}]$ & 50.4092 \\
Fifth order $[\mathrm{Hz}]$ & 50.4428 \\
Sixth order $[\mathrm{Hz}]$ & 76.6961 \\
\hline
\end{tabular}

TABLE 12: The first six-order mode natural frequency of main axis.

\begin{tabular}{lc}
\hline Order & Value \\
\hline First order $[\mathrm{Hz}]$ & 8.35907 \\
Second order $[\mathrm{Hz}]$ & 8.35938 \\
Third order $[\mathrm{Hz}]$ & 52.2301 \\
Fourth order $[\mathrm{Hz}]$ & 52.2319 \\
Fifth order $[\mathrm{Hz}]$ & 145.56 \\
Sixth order $[\mathrm{Hz}]$ & 145.565 \\
\hline
\end{tabular}

From Figure 15, the frequency of first order is $18.0535 \mathrm{~Hz}$ and the first-order critical rotational speed of main blade is calculated as following formula:

$$
n_{0}=60 f
$$

The first-order critical rotational speed $n_{0}$ is $1083 \mathrm{r} / \mathrm{min}$, which is higher than rotational speed of main blade. It means that the resonance of main blade will not occur during operation.

4.2. Drag Rotor. The model of drag rotor used in the modal analysis is the same as the static analysis. Similarly the frequencies of first six-order modes are shown in Table 11 and the vibration modes are shown in Figure 16.

From Figure 16, the natural frequency of first-order is $50.2653 \mathrm{~Hz}$, and the first critical rotational speed of drag rotor calculated by the formula (4) is $3016 \mathrm{r} / \mathrm{min}$. The rotational speed of drag rotor is far lower than the critical rotational speed, which means that the resonance of blade will not occur during the operation.

4.3. Main Axis. The main axis is one of the important parts of wind rotor and nacelle, which not only needs to check the strength and stiffness but also avoid resonance phenomenon. Therefore, based on the model of static mechanical property analysis, the natural frequencies of first six-order modes of main axis are shown in Table 12 and the vibration mode of main axis are shown in Figure 17.

From Figure 17, the frequency of first-order mode is $8.35907 \mathrm{~Hz}$. When the wind rotor works at the rotational speed $100 \mathrm{r} / \mathrm{min}$, the exciting frequency subjected by main axis from wind rotor is $1.667 \mathrm{~Hz}$. However, the natural frequency of first-order is $8.35907 \mathrm{~Hz}$ and it is higher than 


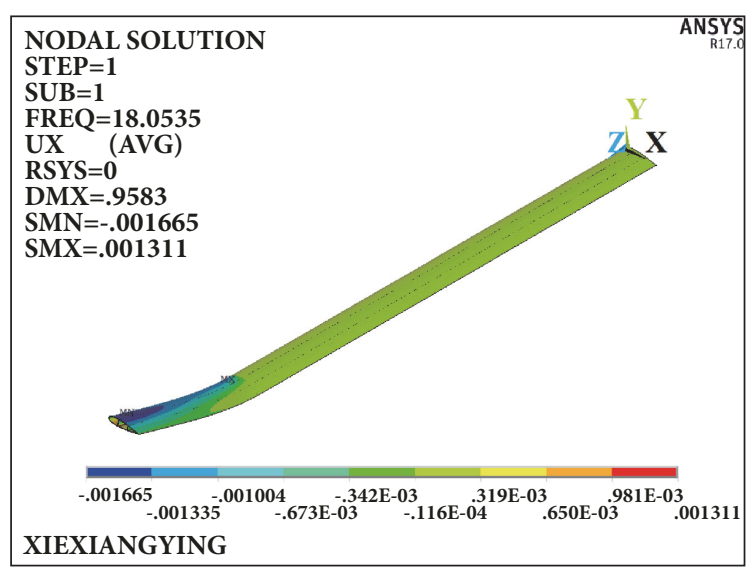

(a) First-order mode vibration profile

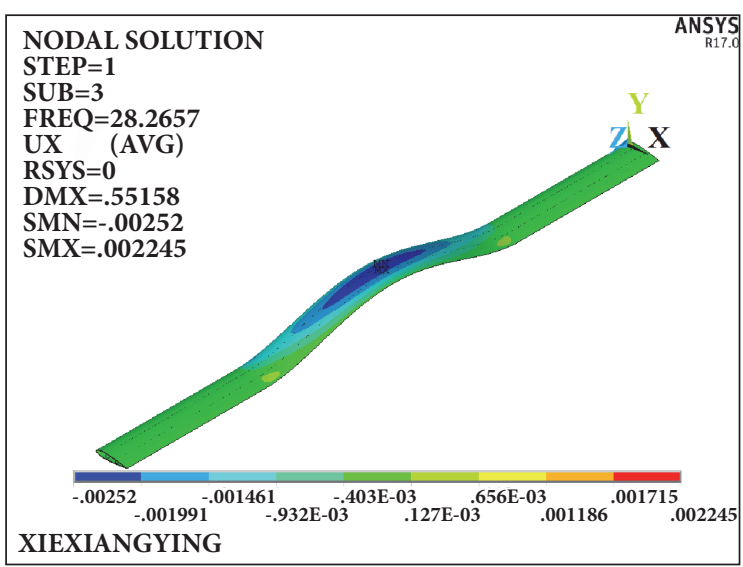

(c) Third-order mode vibration profile

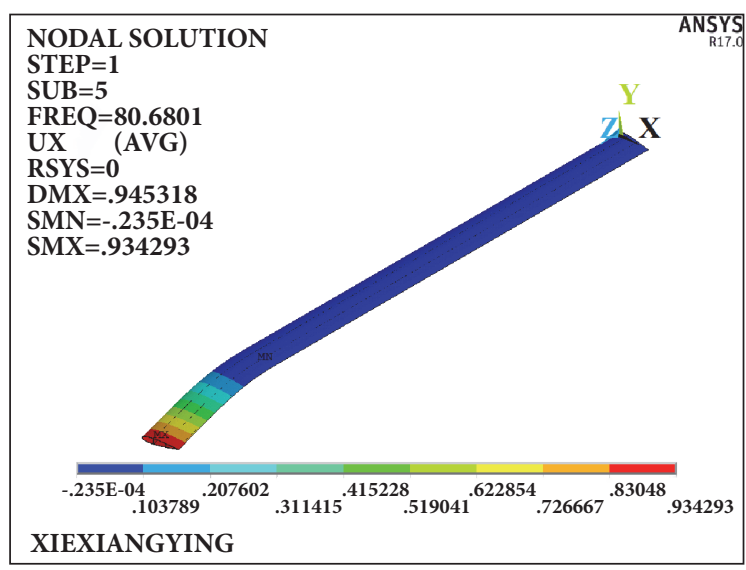

(e) Fifth-order mode vibration profile

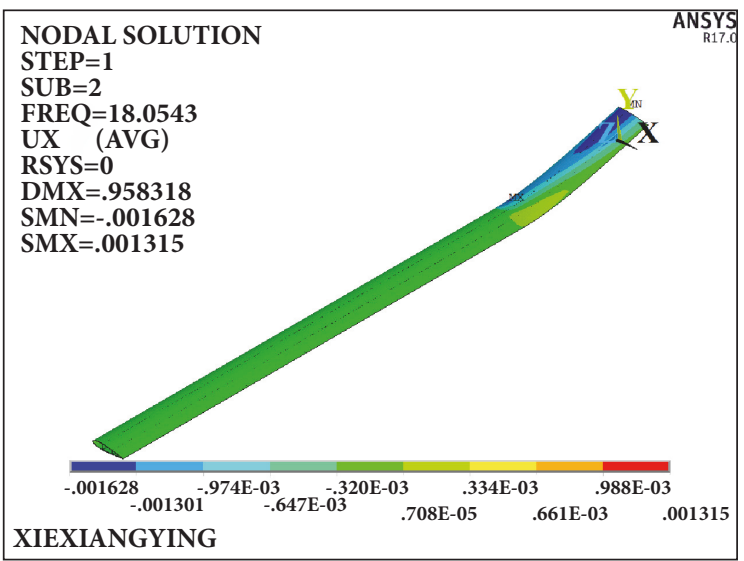

(b) Second-order mode vibration profile

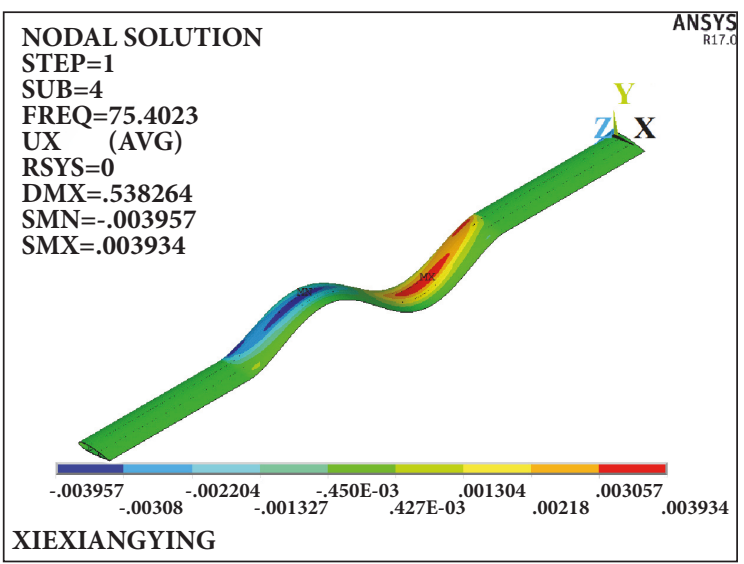

(d) Fourth-order mode vibration profile

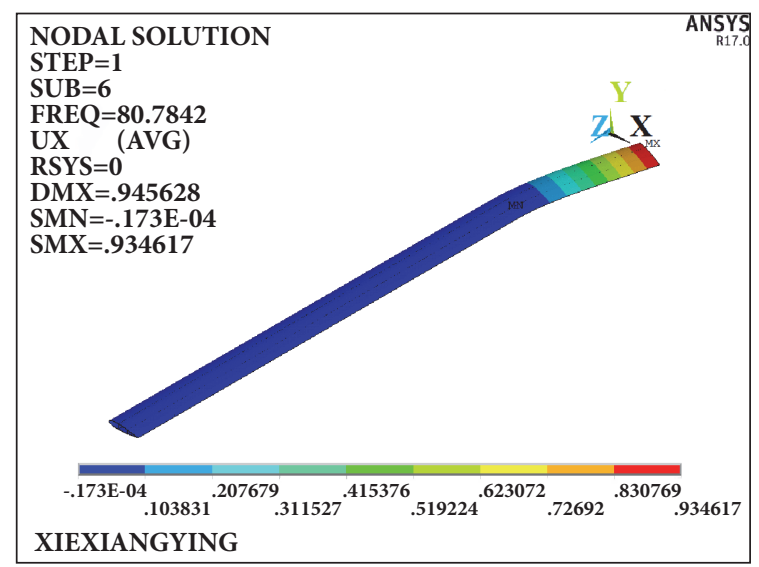

(f) Sixth-order mode vibration profile

FIGURE 15: The first six-order mode vibration profile of main blade.

the work frequency, which means that the resonance will not occur during the operation.

4.4. Tower. Similarly the FEM model of tower in the modal analysis is the same as the static mechanical property analysis and the contact surfaces between tower and ground are constrained. The natural frequencies of first six-order mode of tower are shown in Table 13, and the vibration modes of tower are shown in Figure 18.

From Figure 18, the frequency of first-order mode is 15.2166 Hz. According to what has been mentioned previously the frequency $f_{1}$ of wind rotor under the rated speed is 


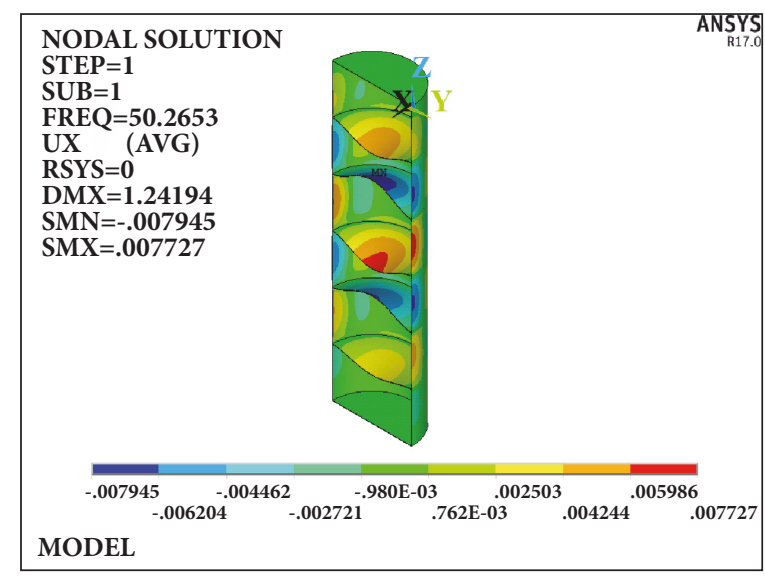

(a) First-order mode vibration profile

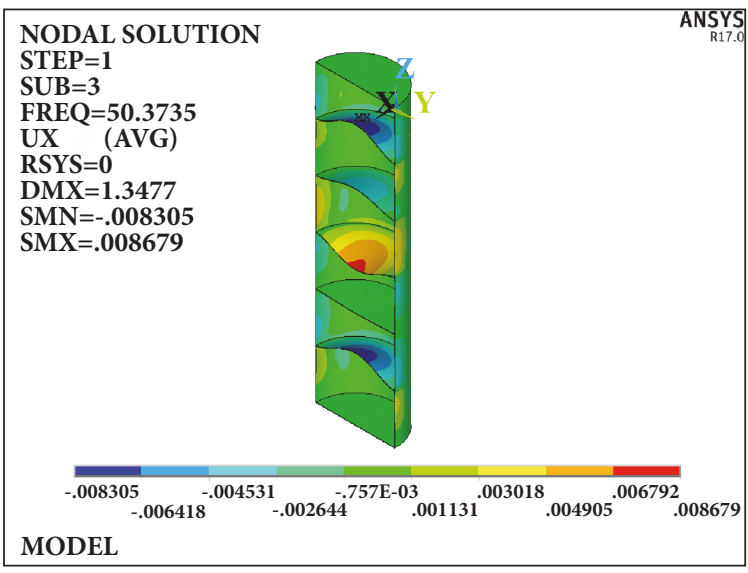

(c) Third-order mode vibration profile

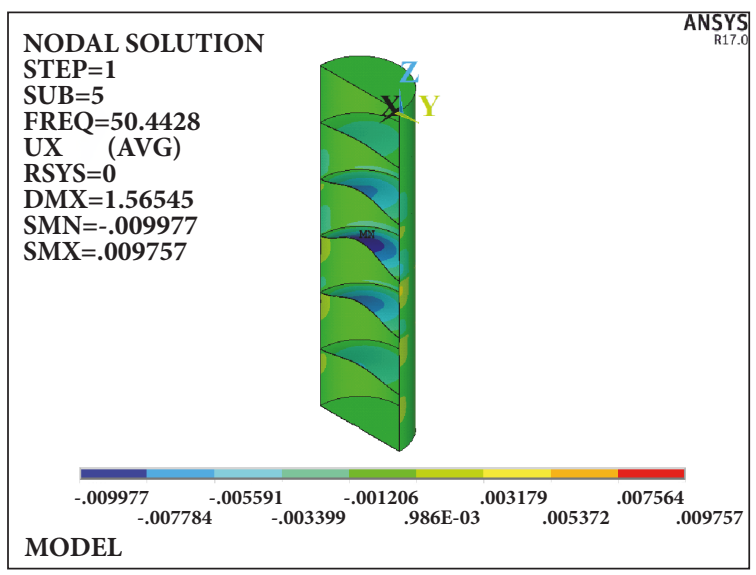

(e) Fifth-order mode vibration profile

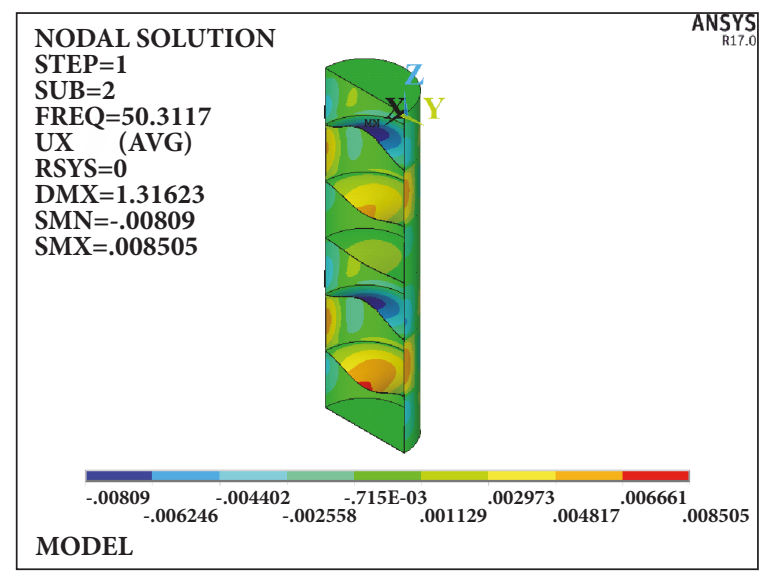

(b) Second-order mode vibration profile

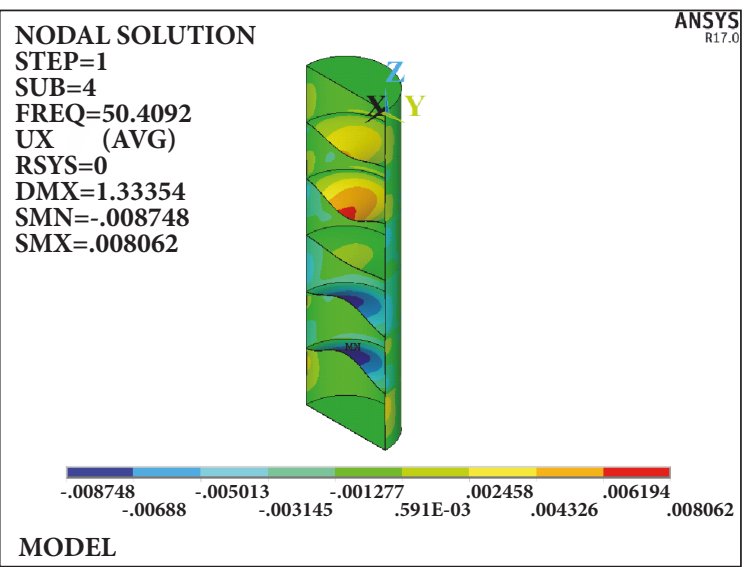

(d) Fourth-order mode vibration profile

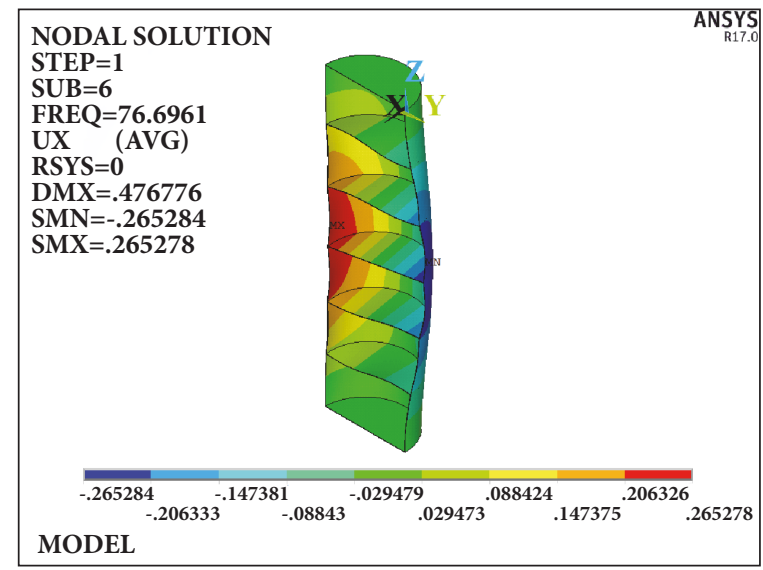

(f) Sixth-order mode vibration profile

FIGURE 16: The first six-order mode vibration profile of drag rotor.

TABLE 13: The first six-order mode natural frequency of tower.

\begin{tabular}{lr}
\hline Order & Value \\
\hline First order $[\mathrm{Hz}]$ & 15.2166 \\
Second order $[\mathrm{Hz}]$ & 15.2166 \\
Third order $[\mathrm{Hz}]$ & 88.6749 \\
Fourth order $[\mathrm{Hz}]$ & 88.6749 \\
Fifth order $[\mathrm{Hz}]$ & 120.362 \\
Sixth order $[\mathrm{Hz}]$ & 168.738 \\
\hline
\end{tabular}




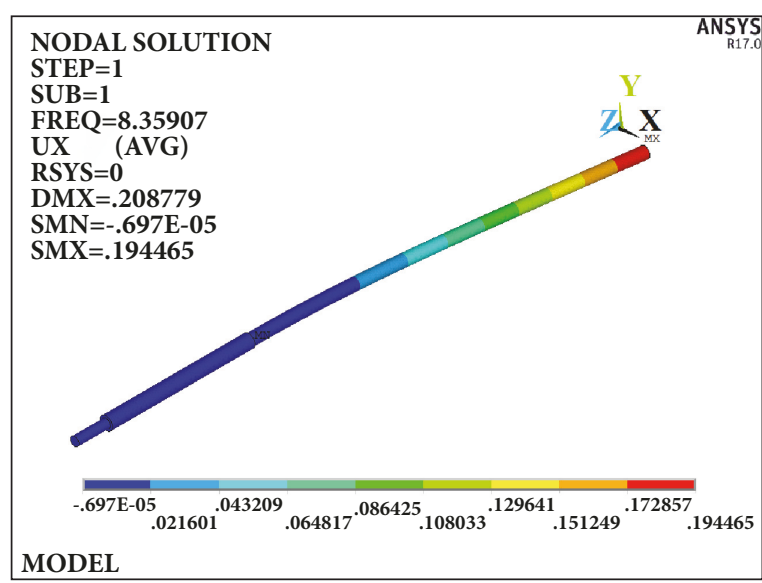

(a) First-order mode vibration profile

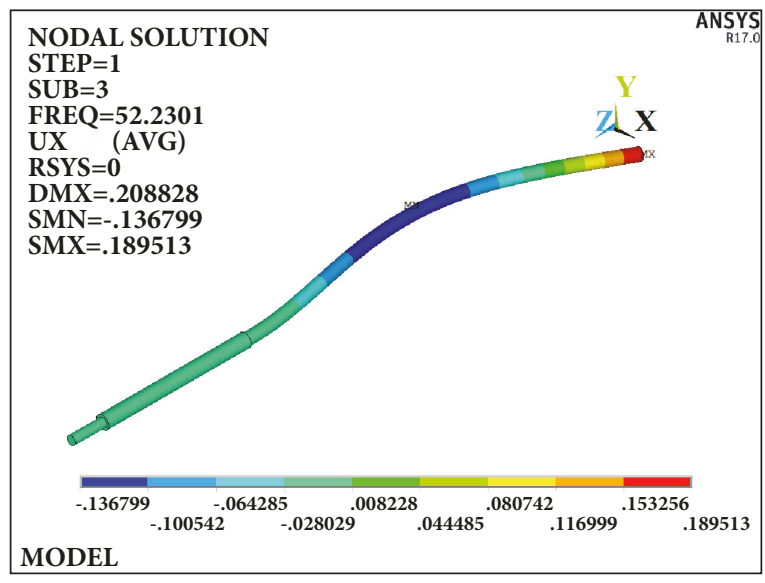

(c) Third-order mode vibration profile

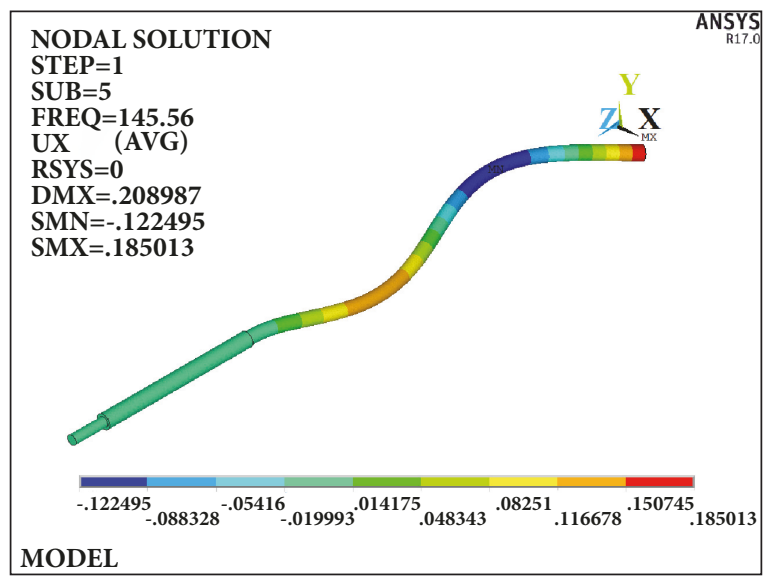

(e) Fifth-order mode vibration profile

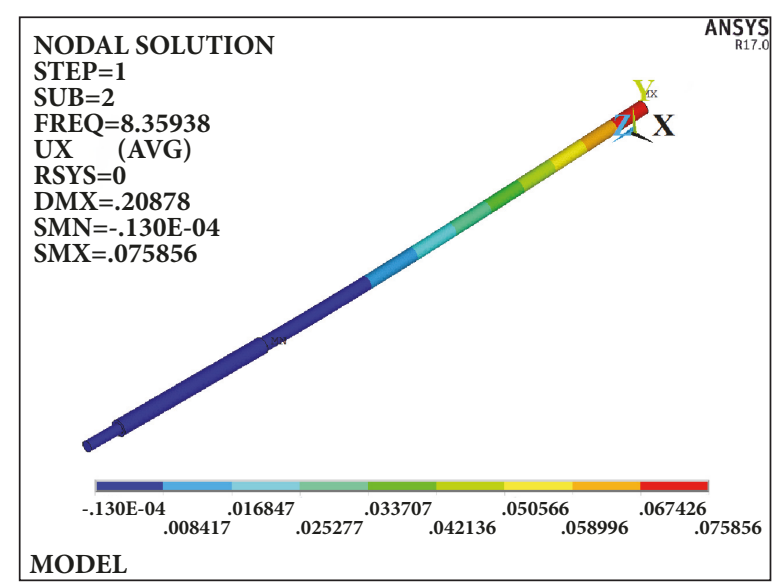

(b) Second-order mode vibration profile

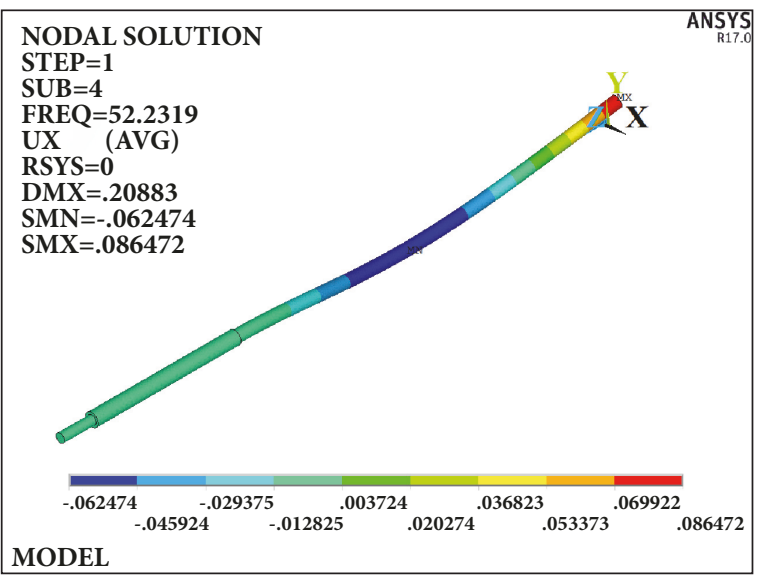

(d) Fourth-order mode vibration profile

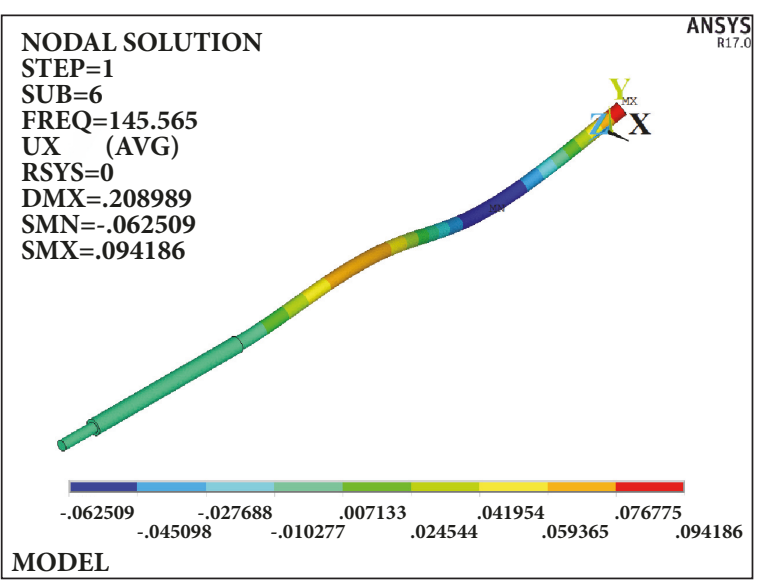

(f) Sixth-order mode vibration profile

FIGURE 17: The first six-order mode vibration profile of main axis.

1.67 Hz. The wind rotor has three blades; therefore the passage frequency $f_{2}$ of the main blades is $5.01 \mathrm{~Hz}$. According to the engineering experience [26], the first-order frequency $f_{01}$ of tower must be higher than the passage frequency $f_{2}$ of the blade and meet the formula:

$$
\frac{\left(f_{01}-f_{02}\right)}{f_{2}} \geq 10 \%
$$

The calculated results meet above conditions, which means that the excitation of wind rotor will not cause the tower to resonate.

\section{Prototype of LD-VAWT}

According to the design of LD-VAWT with the static mechanical property and modal analysis, the results show 


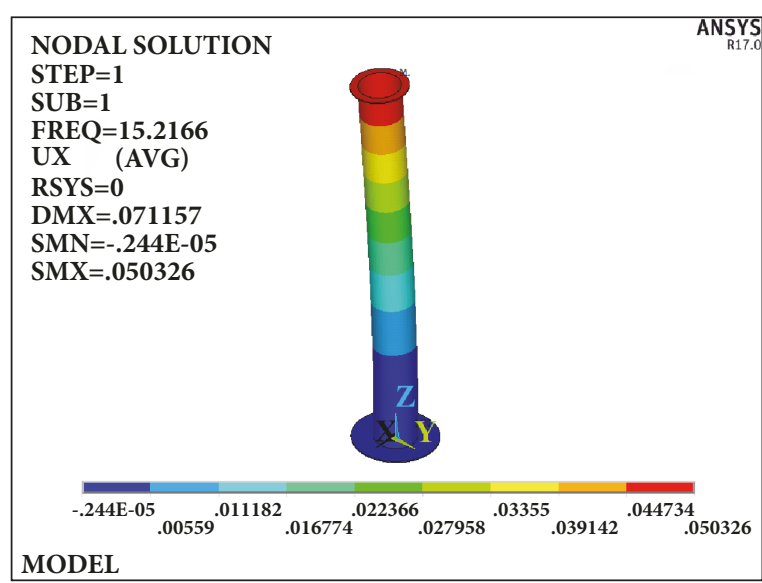

(a) First-order mode vibration profile

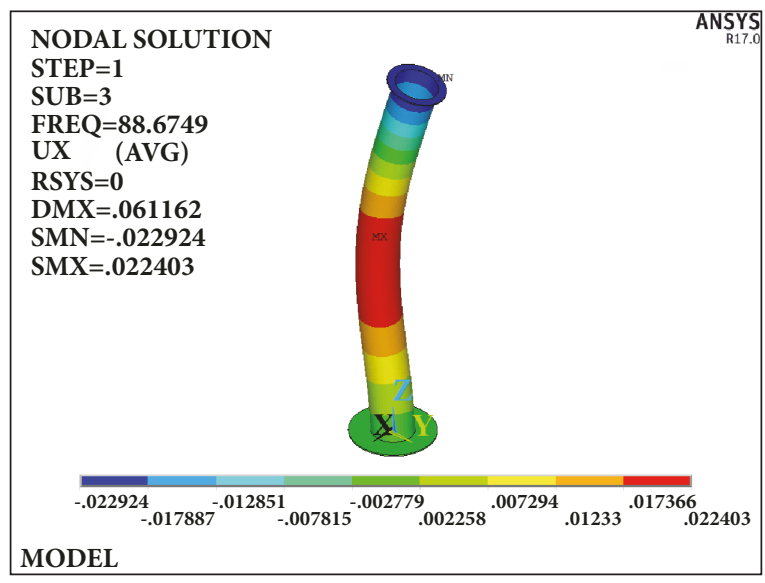

(c) Third-order mode vibration profile

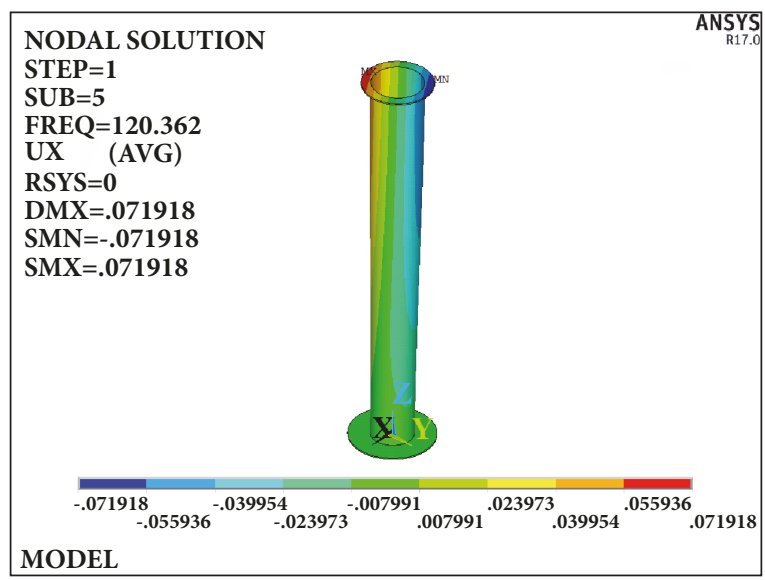

(e) Fifth-order mode vibration profile

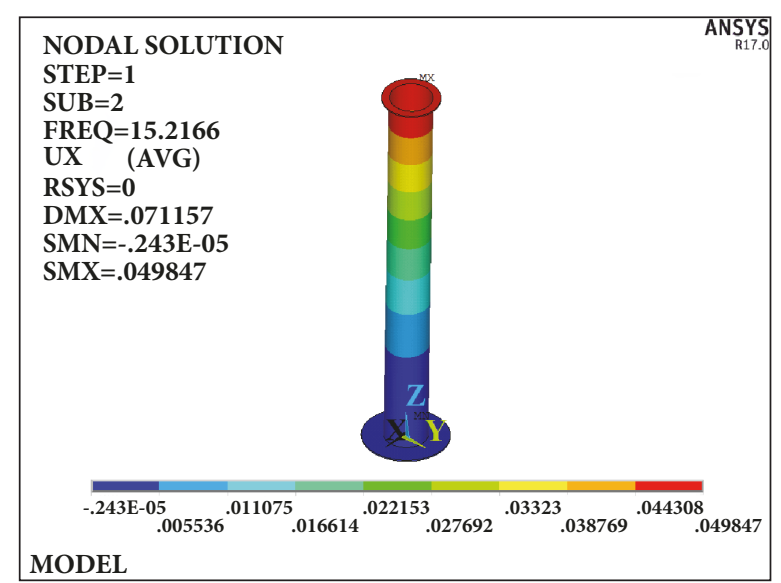

(b) Second-order mode vibration profile

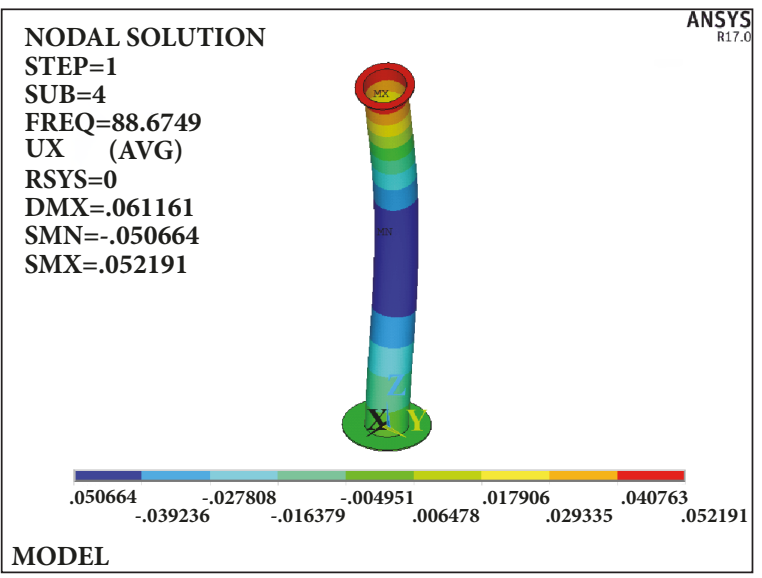

(d) Fourth-order mode vibration profile

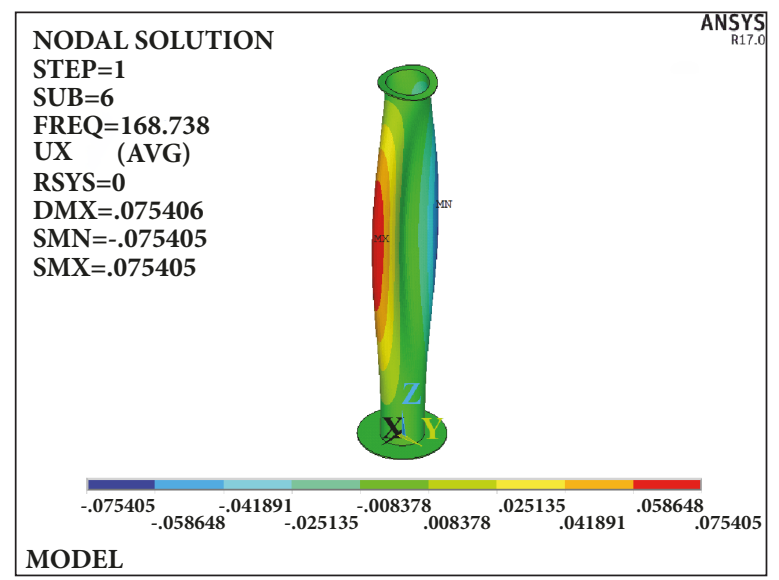

(f) Sixth-order mode vibration profile

FIgURE 18: The first six-order mode vibration profile of tower.

that the design of wind turbine structure is reasonable. A prototype of LD-VAWT was designed and made. It was tested in a farm of Northeast Agricultural University of China which is shown in Figure 19.

Based on the observation of its operation situation for a period of time, the wind turbine can work safely and stably according to the design goal, which shows that the design scheme is practicable and proves that the ideas and methods for LD-VAWT are correct. The paper provides references to analyze the structure of the LD-VAWT.

\section{Conclusions}

In order to explore a set of methods about designing and analyzing the structure of LD-VAWT, the paper took a small-scale LD-VAWT as an example and analyzes the static 


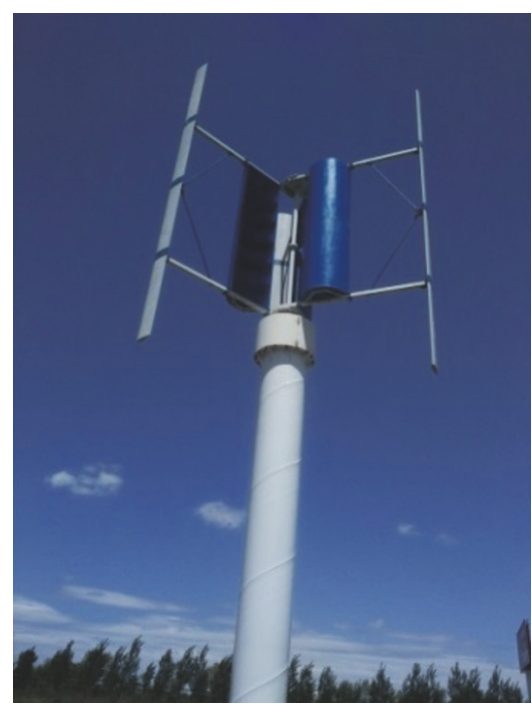

FIGURE 19: Actual machine of wind turbine.

mechanical property and modal analysis by finite element method; the conclusions are as follows.

The corresponding contours of stress and deformation were obtained by using ANSYS to analyze the static mechanical property of main parts of wind turbine, which concludes that the structure of wind turbine meets the design requirements.

The first six-order mode vibration profiles of main parts were also obtained based on the modal analysis, which concludes that the resonance of each main part will not resonant during the operation.

The prototype LD-VAWT was made based on the analysis and simulation results in this study and operated steadily. The methods used in this study can be used as a reference for the static mechanical properties and modal analysis of vertical axis wind turbine.

\section{Conflicts of Interest}

The authors declare that they have no conflicts of interest.

\section{Acknowledgments}

This research is sponsored by the Project 2017MS02 supported by the Foundation of Key Laboratory of Wind Energy and Solar Energy Technology, Ministry of Education. The authors thank the supporter.

\section{References}

[1] Y. Li, Y. Zheng, S. Zhao et al., "A review on aerodynamic characteristics of straight-bladed vertical axis wind turbine," Acta Aerodynamica Sinica, vol. 35, no. 6, pp. 368-382, 2017.

[2] G. Dai, Z. Xu, K. Huangfu, and Y.-J. Zhong, "Research progress in the vertical axis wind turbine," Fluid Machinery, vol. 38, no. 10, pp. 39-43, 2010.

[3] Y. Li, J. Tang, K. Tagawa, and F. Feng, "Effect of frustum-shaped wind collection pattern to starting performance of VAWT,"
Journal of Northeast Agricultural University, vol. 47, no. 4, pp. 95-101, 2016.

[4] Z.-C. Wu, Research on Aerodynamic Characteristics of Vertical Axis Wind Turbine with Eccentric Rotor Structure, Harbin, Northeast Agricultural University, 2017.

[5] M. S. Hameed, S. K. Afaq, and F. Shahid, "Finite element analysis of a composite VAWT blade," Ocean Engineering, vol. 109, pp. 669-676, 2015.

[6] L. Wang, A. Kolios, T. Nishino, P.-L. Delafin, and T. Bird, "Structural optimisation of vertical-axis wind turbine composite blades based on finite element analysis and genetic algorithm," Composite Structures, vol. 153, pp. 123-138, 2016.

[7] T.-T. Zhang, H.-X. Wang, and Z.-B. Dai, "Research on verticalaxis wind turbines structure vibration characteristics," East China Electric Power, vol. 37, no. 3, pp. 452-455, 2009.

[8] J.-Y. Wang, Study of the Effect of Vortex Shedding on a $5 \mathrm{KW}$ H-Type Vertical Axis Wind Turbine, Harbin: Harbin Institute of Technology, 2016.

[9] N. H. Abu-Hamdeh and K. H. Almitani, "Construction and numerical analysis of a collapsible vertical axis wind turbine," Energy Conversion and Management, vol. 151, pp. 400-413, 2017.

[10] Y. Tang, Y. H. Wu, K. Zhang, J. Sun, and E. W. Song, "Finite element analysis of wind turbine lifting platform bridge structure," Applied Mechanics and Materials, vol. 687-691, pp. 398401, 2014.

[11] E. Verkinderen and B. Imam, "A simplified dynamic model for mast design of $\mathrm{H}$-Darrieus vertical axis wind turbines (VAWTs)," Engineering Structures, vol. 100, pp. 564-576, 2015.

[12] Z. Li and Y. Chen, "Dynamic research with drivetrain simulation and modal analysis of wind turbine gearbox," Advanced Materials Research, vol. 952, pp. 161-164, 2014.

[13] I. Paraschivoiu, Wind Turbine Design with Emphasis on Darrieus Concept, Shanghai: Shanghai Scientific \& Technical Publishers, 2013, translated by C. Li.

[14] Y.-H. Zhu and Z.-H. Liu, "Structure and performance analysis for hybrid vertical axis wind turbines with lift and resistance leaves," East China Electric Power, vol. 36, no. 7, pp. 99-101, 2008.

[15] F. Feng, Y. Li, L. Chen, W. Tian, and Y. Zhang, "A simulation and experimental research on aerodynamic characteristics of combined type vertical axis wind turbine," Acta Energiae Solaris Sinica, vol. 35, no. 5, pp. 855-860, 2014.

[16] Q.-B. He, Study on Calculation of Structure And Aerodynamic Characteristics for Vertical Axis Wind Turbine with DoubleLayer Retractile Blades, Harbin: Northeast Agricultural University, 2015.

[17] K. Niklas, "Strength analysis of a large-size supporting structure for an offshore wind turbine," Polish Maritime Research, vol. 24, no. 1, pp. 156-165, 2017.

[18] J.-F. Ji, Z.-Y. Deng, L. Jiang, and D.-G. Huang, "5kW masking the optimization design of the lift vertical axis wind turbine," Journal of Engineering Thermal Physics, vol. 33, no. 7, pp. 560564, 2013.

[19] W. Kou, B. Yuan, Q. Li, and L.-T. Fan, “The structural design of a type of vertical shaft wind generator," Electrical and Electronic Engineering, vol. 27, no. 5, pp. 25-28, 2011.

[20] Z. Xu, Y.-L. Huo, Y. Chen, H.-W. Yang, and H.-F. Tan, “Optimum design and study on the properties of a new combined type vertical axis wind turbine," Journal of Zhejiang University of Technology, vol. 43, no. 3, pp. 261-264, 2015.

[21] J.-J. Qu, M.-W. Xu, Z.-J. Li, and C. Zhi, "A kind of lift and drag hybrid vertical axis wind turbine," Renewable Energy Resources, vol. 28, no. 1, pp. 101-104, 2010. 
[22] K. Kong, X. L. Zhou, and M.-Z. Cheng, "Structural modelling analysis and testing of wind turbine rotor blade," Mechanical Electrical Engineering Technology, vol. 47, no. 5, pp. 45-48, 2018.

[23] GB/T 29494-2013 Small vertical axis wind turbines [S].

[24] GB/T 13981- Design general requirements for small wind turbine[S],

[25] X. Sun, Y. Chen, Y. Cao, G. Wu, Z. Zheng, and D. Huang, "Research on the aerodynamic characteristics of a lift drag hybrid vertical axis wind turbine," Advances in Mechanical Engineering, vol. 8, no. 1, 2016.

[26] X. Song and J.-X. Dai, "Mechanical modeling and ANSYS simulation analysis of horizontally axial wind turbine tower," Journal of Gansu Sciences, vol. 23, no. 1, pp. 91-95, 2011. 


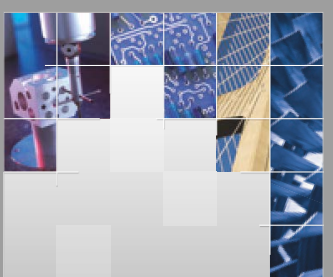

\section{Enfincering}
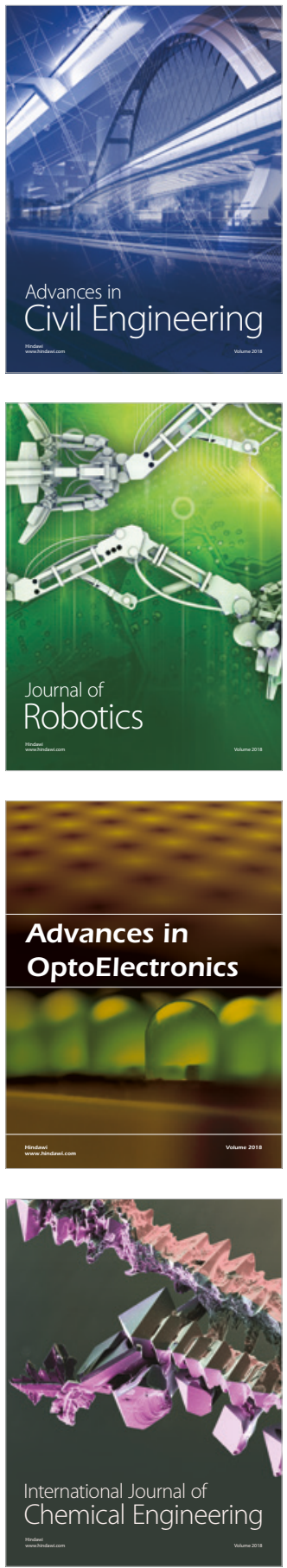

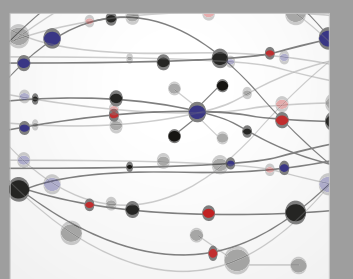

\section{Rotating \\ Machinery}

The Scientific World Journal

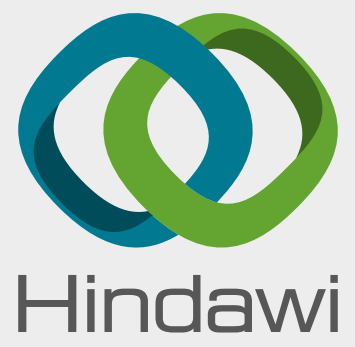

Submit your manuscripts at

www.hindawi.com
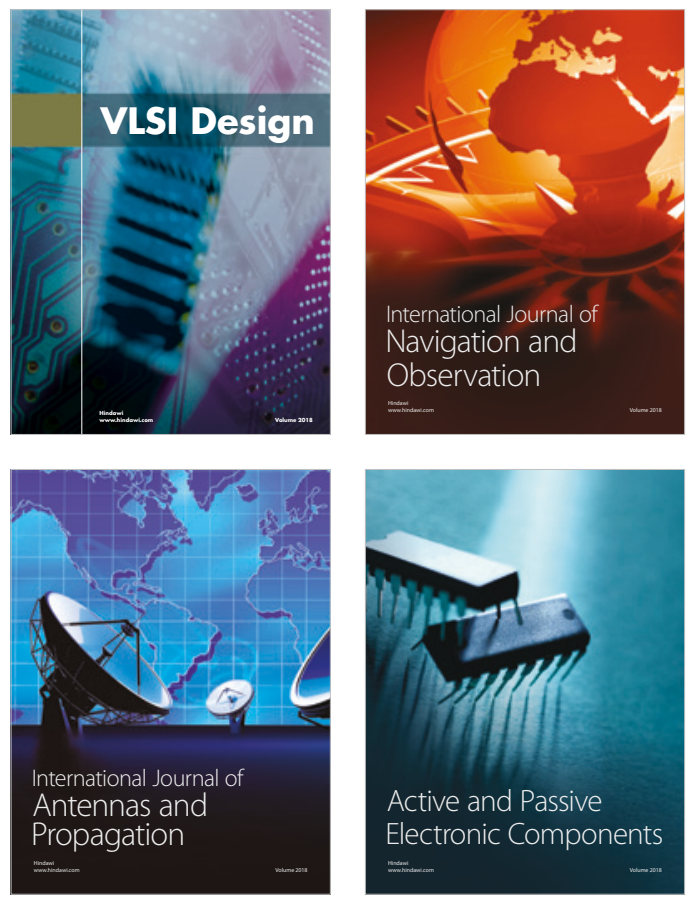
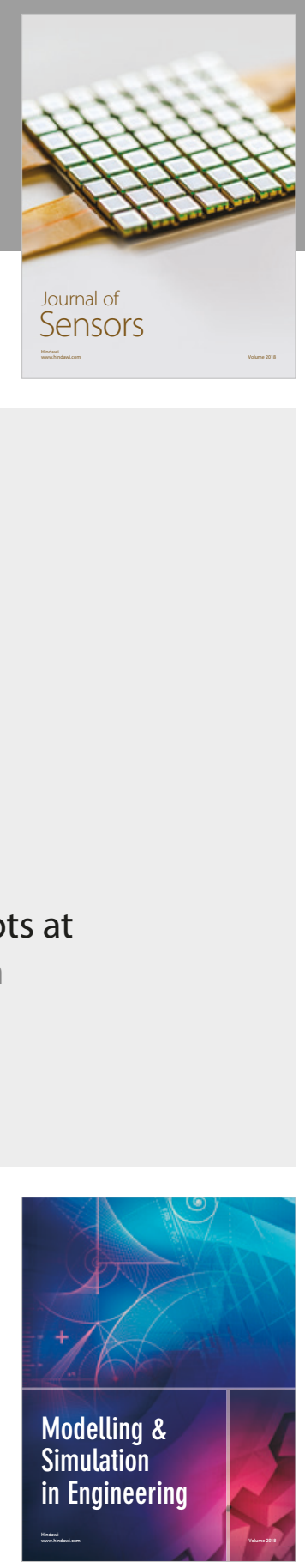

\section{Advances \\ Multimedia}
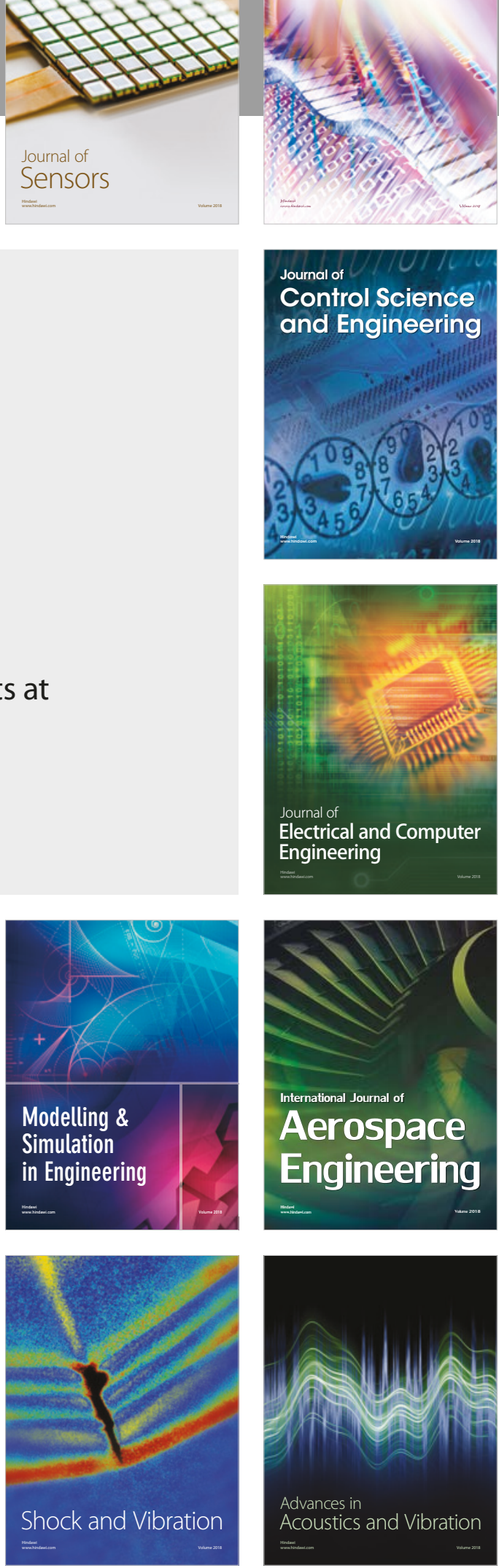